\title{
Pancreoprotective Effect of Jicama (Pachyrhizus erosus, Fabaceae) Fiber against High-Sugar Diet in Mice
}

\author{
Putra Santoso $^{1 *}$, Rita Maliza ${ }^{2}$, Resti Rahayu ${ }^{1}$, Astri Amelia $^{1}$ \\ ${ }^{1}$ Department of Biology, Faculty of Mathematics and Natural Sciences, Andalas University Kampus UNAND Limau Manis Pauh \\ Padang, West Sumatra 25162, Indonesia; ${ }^{2}$ Department of Biology, Faculty of Sciences and Applied Technology, Ahmad Dahlan \\ University, Yogyakarta, Indonesia
}

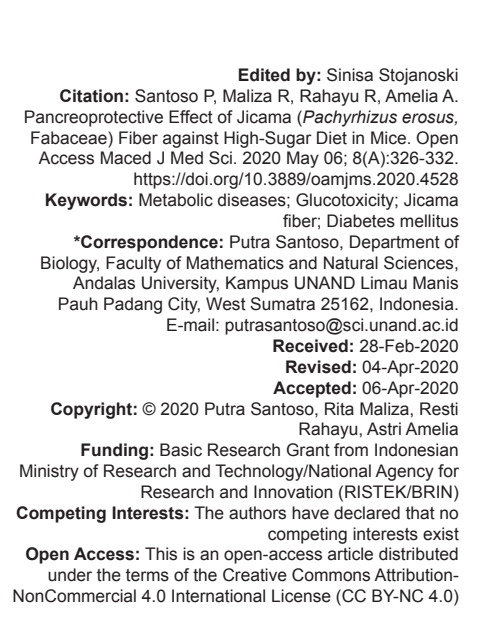

\section{Abstract}

AIM: Jicama (Pachyrhizus erosus, Fabaceae) has been promoted as a potent tuberous plant exerting both preventive and therapeutic effects against many diseases. In this present study, we aimed to investigate the pancreoprotective effect of isolated jicama fiber (JF) against glucotoxicity caused by high-sugar diet (HSD).

METHODS: We performed an animal experimental research using adult male BALB/c mice with a completely randomized design consisted of four treatments and six replications. The treatments were diet types such as normal diet and HSD, supplemented with $10 \%$ and $25 \%$ of JF, respectively. The treatments were deployed for 8 weeks. Furthermore, random and fasting blood glucose levels were measured; histopathological alterations of pancreas including pancreatic adiposity, size of islet area, total cell number per islet, and necrosis level of pancreatic acinar cells were examined. Quantitative data were analyzed using an ANOVA followed by Duncan's new multiple range test $(p<0.05)$.

RESULTS: Our results demonstrate that supplementation of JF $10 \%$ and $25 \%$ improved blood glucose profile and significantly reduced inter pancreatic adiposity caused by HSD. Moreover, JF at the dose of $25 \%$ effectively sustained normal size of the islet of Langerhans and total cell number of the islet in pancreas of HSD-fed mice. JF $25 \%$ was also effective to counteract necrosis of pancreatic acinar cells.

CONCLUSION: Our findings clarify a protective effect of JF, particularly at a dose of $25 \%$, on pancreatic tissues against degeneration caused by HSD. Hence, JF is reliable to be a supplement counteracting the development of diabetes mellitus and associated diseases.

\section{Introduction}

Jicama (Pachyrhizus erosus; Fabaceae) is one of the potential agricultural products cultivated widely for centuries in almost all parts of the world including in Indonesia [1]. An edible jicama tuber is composed of various bioactive compounds including ascorbic acid, flavonoids, thiamine, riboflavin, and inulin [2], [3]. Mounted evidence has demonstrated profound beneficial effects of consuming jicama tuber, served as fresh or processed food, on health. A study in mice as a model of type 2 diabetes elucidated that after a 6-week treatment using jicama extract, the blood glucose, as well as $\mathrm{HbA} 1 \mathrm{c}$ as the objective measure of glycemic control were markedly decreased [4]. Moreover, the tolerances on glucose and insulin were significantly improved and the profile of hepatic metabolism was fully recovered, suggesting an insulin-sensitivity promoting effect of jicama extract against diabetes progression. In another experiment using streptozotocin-injected mice (as a model of type 1 diabetes) suggested a strong inhibitory effect of jicama extract against the activity of $\alpha$-glucosidase and $\alpha$ - amylase to subsequently suppress postprandial blood glucose elevation [5]. Furthermore, a study in healthy human subjects observed a stimulatory effect of jicama juice on circulatory nitrate and nitrite levels thereby preclude an aggregation of platelet caused by collagen [6], indicating a cardiovascular health promoting effect of consuming fresh jicama tuber.

Although the investigations revealing the medicinal benefits of jicama extract have been extensively carried out, studies specifically focusing on the physiological effects of dietary fiber isolated from jicama tuber remain limited. An in vitro experiment showed that jicama fiber (JF) facilitated the production of IgM in HB4C5 cell lines (human hybridoma cells), while in vivo experiment revealed that oral administration of JF promoted serum Ig increase including IgG, $\lg \mathrm{M}$, and $\lg \mathrm{A}$ in mice [7]. Such findings suggest an immunomodulatory effect of JF. Moreover, our previous investigation also found that the supplementation of JF could significantly improve glucose tolerance, sustained normal adiposity profile, and precluded excessive body weight gain in mice treated with high-sugar diet (HSD) for 8 weeks [8]. Our another study also clarified a preventive effect of JF against HSD-induced hepatic 
steatosis in mice [9]. Thus, the beneficial effects of JF against high-calorie diet-induced metabolic diseases become evident. However, it remains unclear whether such health promoting effects exerted by JF are also attributed to its capability in protecting the pancreas against glucotoxicity.

Considering profound implications of having high fiber intake on counteracting the development and progression of various metabolic diseases including obesity and diabetes mellitus [10], [11], [12], [13], [14], we, therefore, in this current work, performed an experiment to unravel the protective effect of JF against HSD-induced pancreatic degeneration using adult male mice as the animal model. Our findings highlight an apparent medicinal benefit of consuming isolated JF to preclude the detrimental effects of sugary food promoting pancreatic deterioration and subsequent blood sugar dysregulation.

\section{Materials and Methods}

\section{Research type and design}

In this current study, we carried out an animal experimental research with a completely randomized design consisted of four treatments and six replications using healthy adult male mice as the test animals. The treatments were diet types deployed for 8 consecutive weeks as follows:

- $\quad$ Group 1: Mice fed with a normal diet (ND)

- $\quad$ Group 2: Mice fed with a HSD

- $\quad$ Group 3: Mice fed with HSD supplemented with 10\% JF (HSD + JF 10\%)

Group 4: Mice fed with HSD supplemented with $25 \%$ of JF (HSD + JF $25 \%$ ).

The diet compositions are presented in Table 1.

Table 1: Diet composition for experimental treatment

\begin{tabular}{llll}
\hline Diet type & $\%(\mathrm{w} / \mathrm{w})$ & Sucrose & JF \\
\cline { 2 - 4 } & $\mathrm{BP} 2$ & 0 & 0 \\
ND & 100 & 30 & 0 \\
HSD & 70 & 30 & 10 \\
HSD + JF 10\% & 60 & 30 & 25 \\
HSD + JF 25\% & 45 & &
\end{tabular}
sucrose powder combined with ND powder, JF: Jicama fiber.

\section{JF Isolation}

Freshly harvested jicama tubers (3.5-4 months old) were purchased from a local farmer at Padang Pariaman, West Sumatra Province, Indonesia. The tubers were first washed 3 times using tap water before being peeled and sliced to be small pieces. Furthermore, the slices were ground using an electric grater (HR2116-Philips, Indonesia) and the fiber was isolated subsequently using the protocols as we have described elsewhere [8], [9]. Briefly, the sample was soaked into the aquadest overnight at room temperature in an isolated jar. Furthermore, the supernatant consisted of fiber was collected then steamed and dried using an oven $\left(68-70^{\circ} \mathrm{C} ; 16 \mathrm{~h}\right)$. The dried fiber yielded from the isolation process was stored in a sealed jar before being used for the experiment.

\section{Provision of animal model}

Twenty-four adult male mice (BALB/c; 23-25 g) were purchased from UD. Wistar Company, Yogyakarta Indonesia. On arrival in the lab, animals were caged individually in the animal room with a regulated temperature $\left(25-27^{\circ} \mathrm{C}\right)$ and a normal light-dark cycle (12 h dark, $12 \mathrm{~h}$ light). Animals were fed with a ND (Java Comfeed diet; Jakarta Indonesia) and tap water drink ad libitum. This acclimation was carried out for a week before the experimental treatment.

\section{Blood glucose measurement}

Blood glucose levels were measured using an automatic glucometer (Dr Glucose-auto; Allmedicus South Korea) at the beginning ( 0 day) and the end of treatment (8 weeks). The blood sample was drawn gently from the tip of the tail with a minimum injury. Random blood glucose was determined at 9.00 a.m during a non-fasting state while fasting blood glucose was measured after 18-h fasting (18:00-9:00; food deprived but water provided).

\section{Histopathological examination of the pancreas}

The animals were sacrificed at the end of treatment by means of dislocation of vertebrae cervicalis. The pancreas was removed from each individual and subsequently washed with $\mathrm{NaCl} 0.9 \%$ followed by fixation with formaldehyde $10 \%$. The fixed samples were then subjected to histopathological examination microscopically by following the procedures as described previously [15]. The tissues were stained using hematoxylin-eosin staining and observed using a light microscope (Olympus-CX31, Japan). The histological slides were prepared as many as five slices for each animal. The slides were examined under a microscope and photographed. The size of the islet of Langerhans and total cell number per each islet were determined using Image-J software (NIH, USA), while the necrosis level of acinar cells was counted by following the previous method [16]. Lipid deposition in the pancreas tissue (pancreatic adiposity) was descriptively described.

\section{Data analysis}

Quantitative data including random blood glucose level, fasting blood glucose level, size of the islet 
of Langerhans, total cell number per islet, and percentage of necrosis of pancreatic acinar cells were analyzed using a one-way ANOVA followed by the Duncan's New Multiple Range Test ( $p<0.05$ considered as significant).

\section{Results}

In a current study using mice as the animal model, we demonstrated a pancreoprotective effect of JF against the development of diabetes mellitus caused by HSD. As shown in Figure 1a and b, after 8 weeks of treatment, blood glucose in mice fed with HSD supplemented with JF (both 10\% and 25\%) exhibited a normal blood glucose profile (based on random blood glucose and fasting blood glucose level), being comparable with those fed with a (ND, control group). Otherwise, a group treated with HSD alone experienced a hyperglycemia state at the end of treatment. Furthermore, the histological examination on pancreatic tissue found that mice treated with JF showed a markedly reduced interpancreatic adiposity as compared with the HSD-treated group (Figure 2a-d). An observation focused on islet of Langerhans revealed that JF supplementation effectively precluded islet dystrophy (reduction of islet size) caused by HSD (Figure 3a-d). The measurement of the islet area as well as total cell number per islet confirmed that the JF $25 \%$ was significantly sustained the size and total cell number of the islet, being comparable with the control group (ND) (Figure 3e and f). Besides, we also examined the necrotic level of pancreatic acinar cells (Figure 4a-d). The results indicate a marked reduction in number of necrosis in pancreatic acinar cells of mice treated with $\mathrm{JF}$, particularly at the higher dose (25\%). However, such reduction was statistically insignificant at a group treated with a lower dose of JF (10\%) (Figure 4e).

\section{Discussion}

In our previous investigation [8], it was demonstrated that the supplementation of JF sustained a normoglycemic state over the time course of treatment (0-8 weeks) in mice fed with $30 \%$ sucrose powder (HSD). Such a blood glucose profile was also in accordance with normal body weight and adiposity profile, suggesting a preventive effect against diabetes mellitus and obesity development caused by excessive consumption of sugary food. Likewise, in our recent study, we also confirm that random blood glucose and fasting blood glucose, as measured at the end of treatment, were in the normal range in groups treated with JF.

Chronic intake of high concentration sucrose is considerably attributed to a marked increase
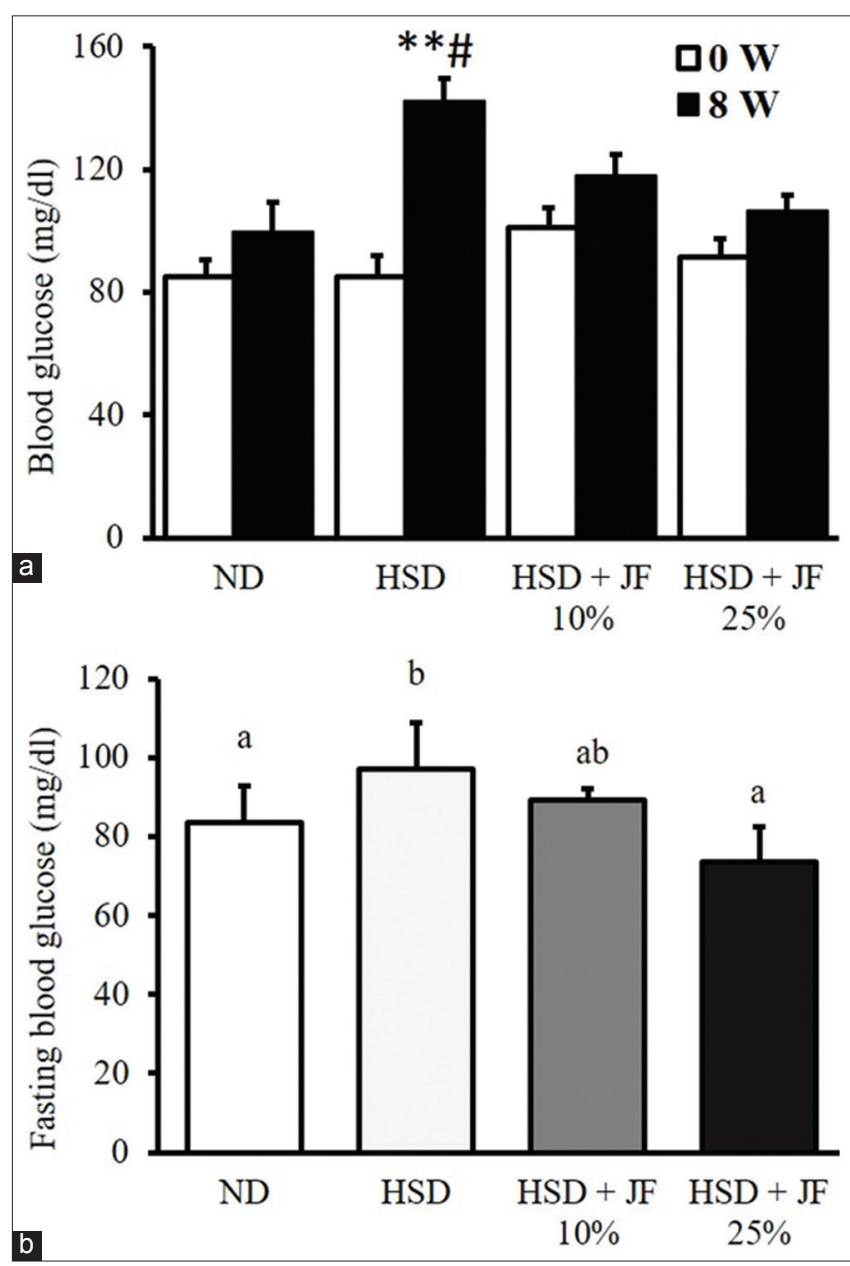

Figure 1: Supplementation of jicama fiber sustained a normal blood glucose level in mice fed with a HSD. (a) Random blood glucose as measured before $(0 \mathrm{~W})$ and after an 8-week treatment $(8 \mathrm{~W})$, (b) fasting blood glucose determined at the end of treatment. ND: Normal diet, HSD: High-sucrose diet, JF: Jicama fiber. ${ }^{* *}$ indicates a significant difference $(p<0.01)$ within the same group with a different time course (0 vs. 8 weeks); \#indicates a significant different of HSD group compared with all other groups. The different characters ( $a$ and $b)$ on the top of bars in $B$ indicate a significantly different $(p<0.01)$ statistically
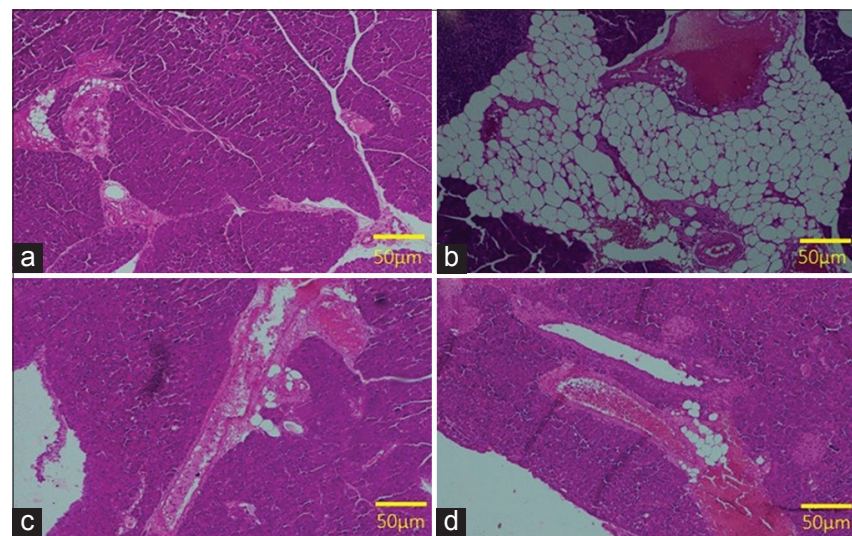

Figure 2: Jicama fiber inhibited fat deposition in the pancreas of mice fed with high-sucrose diet (HSD). Histological feature of pancreatic tissues in (a) normal diet group, (b) HSD group with a severe adipocyte accumulation (white droplets), (c) HSD + Jicama fiber (JF) $10 \%$ group, (d) HSD + JF 25\% group. Tissues were stained with hematoxylin-eosin. Scale bars $=50 \mu \mathrm{m}$ 

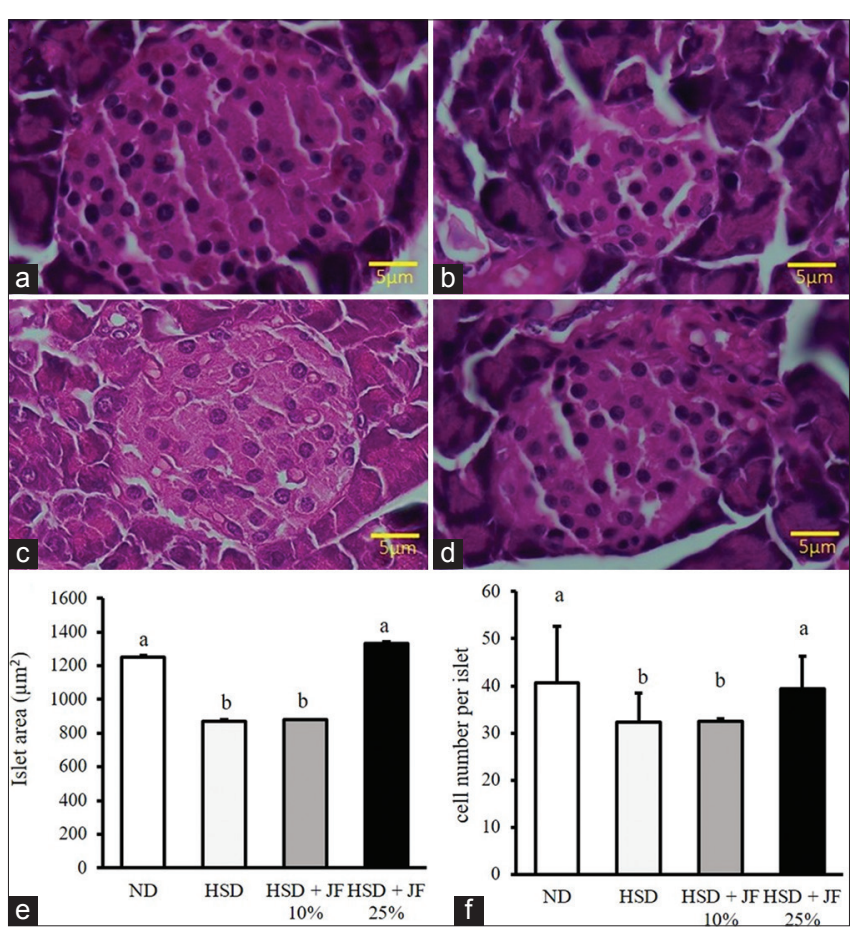

Figure 3: Jicama fiber (JF) prevented islet dystrophy (reduction in the size of the islet of Langerhans) and total cell number per islet in high-sucrose diet (HSD)-fed mice. Histological features of the islet of Langerhans in (a) normal diet group, (b) HSD group, (c) HSD + JF $10 \%$ group, (d) HSD + JF 25\% group, (e and f) depict the islet area and total cell number per islet, respectively. The different characters ( $a$ and $b$ ) on the top of bars in $B$ indicate a significantly difference $(p<0.01)$ statistically. Scale bars in A-D: $5 \mu \mathrm{m}$

of blood glucose and its subsequent pathological outcomes including pancreatic damage and apparent metabolic dysregulations [17]. It has been reported by the previous study [18] that high glucose intake could cause glucotoxicity, a condition in which pancreatic cells including $\beta$ cells and insulin-targeted cells are chronically exposed to a supraphysiological glucose concentration. Insulin release by pancreatic $\beta$ cells is mainly stimulated by blood glucose increase [19]. Causatively, a chronic state of blood glucose increase could lead to hyperinsulinemia due to the overstimulation of $\beta$ cells in synthesizing and releasing insulin. Consequently, the $\beta$ cells undergo an exhausted state thereby experience severe cellular damage. Moreover, hyperinsulinemia has been demonstrated to apparently reduce the insulin receptor's sensitivity in targeted cells and subsequently causes insulin resistance [20]. Such cascading effects, all together, eventually exacerbate dysregulated blood glucose homeostasis to develop diabetes mellitus.

In our study, after an 8-week treatment, the HSD-treated group exhibited only a pre-diabetic state with a random blood glucose level of more than $120 \mathrm{mg} / \mathrm{dl}$ but $<250 \mathrm{mg} / \mathrm{dl}$. However, it was accompanied by the severe histological alterations in the pancreas including excessive ectopic fat accumulation, atrophy of the islet size, marked depletion in total cell number of the islet, as well as a salient increase of necrotic acinar cells. Interestingly, such alterations were lesser or even lack in mice fed with JF, particularly at a higher dose (25\%).
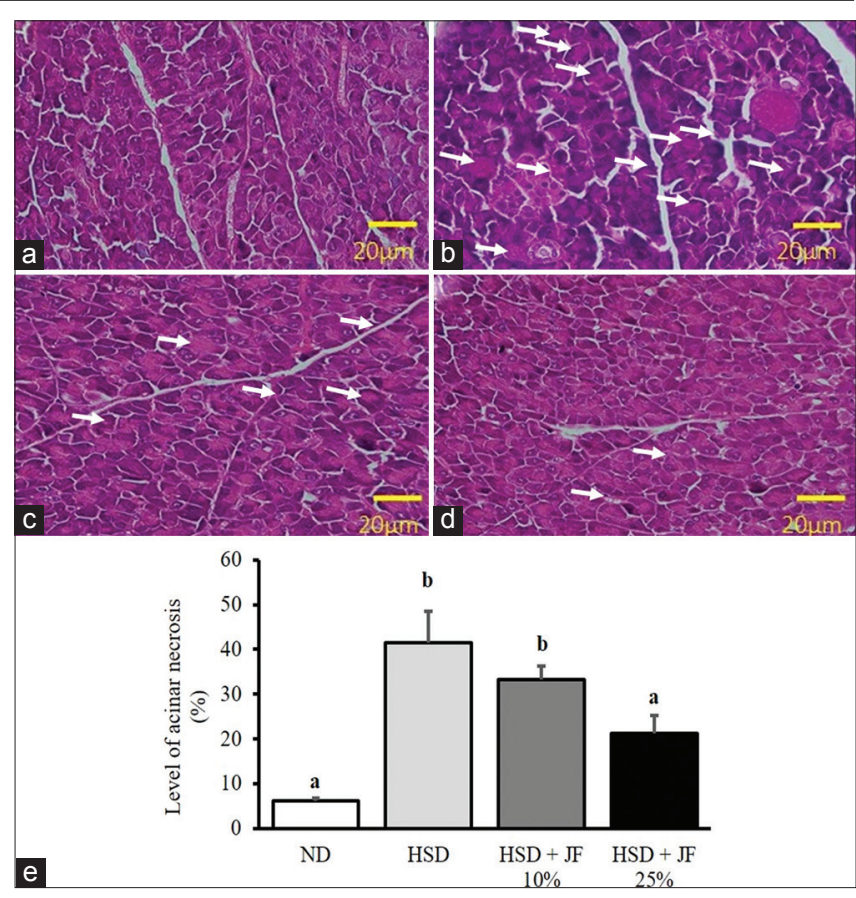

Figure 4: Jicama fiber (JF) precluded the necrosis of pancreatic acinar cells in high-sucrose diet (HSD)-fed mice. Histological features of acinar cells in (a) normal diet group, (b) HSD group, (c) HSD + JF $10 \%$ group, (d) HSD + JF $25 \%$ group. White arrows in panel $B-D$ indicate necrotic cells. (e) Depicts the score of acinar cells' necrosis. The different characters ( $a$ and $b$ ) on the top of bars in $E$ indicate a significantly different $(p<0.01)$ statistically. Scale bars in A-D: $20 \mu \mathrm{m}$

The previous report showed an effective of dietary fiber of bamboo shoot to preclude a surge of blood glucose level under a chronic intake of a high-calorie diet in mice [11]. Another study in humans also revealed a similar finding [13], suggesting an anticipatory effect of dietary fiber against diet-induced diabetes progression.

Ectopic fat accumulated in the pancreas, as observed in the HSD-treated group of our study, reflects the excessive energy depot with minimum energy expenditure. It has been reported that fat accumulation is a primary cause for pancreatic lipotoxicity which eventually promotes cellular damages including the degeneration of pancreatic $\beta$ cells [21]. Ectopic fat also exerts cytokines that will be accompanied by pancreatic inflammation leading to cellular dysfunction. We found that when the HSD-fed mice were supplemented with JF, the ectopic fat accumulation (inter pancreatic adiposity) was rarely exhibited. Therefore, the pathophysiological outcomes that may be associated with lipotoxicity and inflammation in the pancreas were subtle in JF-treated animals.

Pancreatic acinar cells make up $90 \%$ of entire pancreas tissues which specifically function as exocrine by secreting its enzymes (zymogens) into the digestive tract [22]. A study has revealed that such enzymes are capable of affecting blood glucose regulation as well as secretion of insulin by $\beta$ cells, while, reversely, the insulin is also involved in regulating the enzymes [23]. In our study, we found that HSD treatment caused more than $40 \%$ of necrosis in pancreatic acinar cells. 
Hence, we suggest that, under a chronic high blood glucose level, the acinar cells are exhausted due to their excessive enzyme secretion toward a challenge in regulating blood glucose as well as insulin secretion. Moreover, insulin resistance also contributes in exacerbating the exhaustion of acinar cells leading to necrosis. Meanwhile, in animals treated with JF 25\%, the level of necrosis in acinar cells was significantly reduced, suggesting a minimum burden on pancreatic acinar cells. This counteractive effect of JF could be due to a consequence of sustained blood glucose levels as well as sufficient insulin function. Unfortunately, in our study, we did not determine the plasma insulin level that could fully supports our speculation. However, based on our previous study [8], it was proven that the supplementation of JF $25 \%$ significantly improved glucose tolerance in HSD-treated mice. Since that glucose tolerance also reflects the insulin activity, therefore, our speculation regarding the association between sufficient insulin function and lower level of acinar cells' necrosis could be reasonable. A further study measuring the insulin level as well as insulin tolerance is required to clarify our suggestions.

Fiber exerts its physiological effects in many plausible ways to overcome the detrimental effect elicited by a HSD. Fiber could significantly reduce the absorption of sugar in the intestine by slowing down the gastric emptying rate, preventing the digestive enzymes including $\alpha$-amylase as well as increasing the viscosity of the digested food in the intestine [13], [24]. Consequently, the amount of ingested sugar reaching the circulatory portal is lower and its subsequent impacts on metabolic regulation including pancreatic degeneration will be effectively precluded. Moreover, fiber could indirectly affect the physiological process of the body through its fermentation products. It has been reported that the intestinal microbes are capable of fermenting the dietary fiber to produce short-chain fatty acids (SCFAs) including acetate, butyrate, and propionate [12], [25]. Growing evidence confirm diverse physiological benefits of SCFAs. A study [26] showed a stimulatory effect of SCFAs on glucagon-like peptide 1 (GLP-1), a hormone that plays a key role in increasing insulin sensitivity as well as energy expenditure that plausibly could be implicated in pancreatic stability against HSD. Moreover, SCFAs also could counteract the reactive oxygen species-induced oxidative stress promoted by excessive glucose intake [27]. Chronic oxidative stress in the pancreas profoundly leads to apoptosis and defective effect on the expression of insulin gene as well as insulin secretion [28]. Therefore, the higher amount of fiber intake will be correlated with an elevated SCFAs production thereby its protective effect against glucotoxicity-induced structural and functional damages of the pancreas.

In our present study, concerning the research methods, at least two major limitations need to be considered. First, the dose of JF used as treatment consisted only two levels (10\% and $25 \%$ ) that precluded us to demonstrate the efficacy of the other considerable doses (for instances $5 \%, 15 \%$, and $30 \%$ ) in protecting pancreas against HSD. In a preliminary experiment performed for 4 weeks, we observed that $5 \%$ of JF was not effective in lowering blood glucose of HSDfed mice, while a treatment with $30 \%$ of JF caused a severe anorexia indicated by extremely reduction in food intake (data not shown in this current report). However, it remains unclarified by our study whether a prolonged treatment with $5 \%$ and $30 \%$ of JF up to 8 weeks as well as a treatment with a medium dose of JF (e.g., 15\%) could elicit a higher efficacy against HSD effects. Thus, a further study is required to clarify such possibilities. As the second limitation of our recent study, we used a relatively small number of mice in each group of treatment $(n=6)$ that may affect the robustness of statistical interpretation of our significant findings. Hence, even though almost our current data exhibit a lower standard error as indicator of a proper homogeneity with six animals in each group, future study using a larger number of replications is warranted to be performed.

In summary, our recent findings demonstrate that the supplementation of JF, particularly at the dose of $25 \%$, was effective in preventing the inter pancreatic adiposity, islet atrophy, and necrosis of acinar cells leading to elevation of blood glucose level in mice. Further studies elucidating the effects of JF on pancreatic regeneration, SCFAs level, intestinal microbiota diversity, and level of metabolic hormone including GLP-1 and PYY are needed to deepen our understanding on the mechanism of JF in promoting normal metabolic profiles against HSD-induced diseases progression.

\section{Conclusion}

Our study revealed that JF at the dose of $25 \%$ could significantly exert a preventive effect against HSDinduced pancreatic degeneration as well as elevated blood glucose level. Therefore, JF is reliable to be a supplement counteracting the development of diabetes mellitus and associated metabolic disturbances.

\section{Acknowledgment}

This work was funded by Indonesian Ministry of Research and Technology/National Agency for Research and Innovation (RISTEK/BRIN; 163/SP2H/ AMD/LT/DRPM/2020) designated for P. Santoso and R. Maliza. The authors thank Siti Jamalul Insani, BSc. and 
Qonita Fadhilah, BSc. (Biology Department, Andalas University) for their help in animal maintenance.

\section{Contribution of Authors}

P. Santoso and R. Maliza designed the study; P. Santoso, R. Rahayu, A. Amelia performed the experiments; P. Santoso and R. Maliza prepared the manuscript. All authors read and revised the manuscript.

\section{References}

1. Nursandi F, Machmudi M, Santoso U, Indratmi D. Properties of different aged jicama (Pachyrhizus erozus) plants. IOP Conf Ser. 2017;77:12003. https://doi.org/10.1088/1755-1315/77/1/012003

2. Buckman ES, Oduro I, Plahar WA, Tortoe C. Determination of the chemical and functional properties of yam bean (Pachyrhizus erosus (L.) urban) flour for food systems. Food Sci Nutr. 2017;6(2):457-63. https://doi.org/10.1002/fsn3.574 PMid:29564113

3. Noman AS, Hoque MA, Haque MM, Pervin F, Karim MR. Nutritional and anti-nutritional components in Pachyrhizus erosus L. Tuber. Food Chem. 2007;102(4):1112-8. https://doi. org/10.1016/j.foodchem.2006.06.055

4. Park CJ, Lee HA, Han JS. Jicama (Pachyrhizus erosus) extract increases insulin sensitivity and regulates hepatic glucose in C57BL/Ksj db/db mice. J Clin Biochem Nutr. 2015;58(1):56-63. https://doi.org/10.3164/jcbn.15-59

PMid:26798198

5. Park CJ, Han JS. Hypoglycemic effect of jicama (Pachyrhizus erosus) extract on streptozotocin-induced diabetic mice. Prev Nutr Food Sci. 2015;20(2):88-93. https://doi.org/10.3746/ pnf.2015.20.2.88

PMid:26175995

6. Thaptimthong T, Kasemsuk T, Sibmooh N, Unchern S. Platelet inhibitory effects of juices from Pachyrhizus erosus L. root and Psidium guajava L. fruit: A randomized controlled trial in healthy volunteers. BMC Complement Altern Med. 2016;16:269. https:// doi.org/10.1186/s12906-016-1255-1

PMid:27488183

7. Kumalasari ID, Nishi K, Harmayani E, Raharjo S, Sugahara T. Immunomodulatory activity of Bengkoang (Pachyrhizus erosus) fiber extract in vitro and in vivo. Cytotechnology. 2014;66(1):75-85. https://doi.org/10.1007/s10616-013-9539-5 PMid:23361525

8. Santoso P, Amelia A, Rahayu R. Jicama (Pachyrhizus erosus) fiber prevents excessive blood glucose and body weight increase without affecting food intake in mice fed with highsugar diet. J Adv Vet Res Anim Sci. 2019;6(2):222-30. https:// doi.org/10.5455/javar.2019.f336

PMid:31453195

9. Santoso P, Maliza R, Fadhila Q, Insani SJ. Beneficial effect of Pachyrhizus erosus fiber as a supplemental diet to counteract sugar-induced fatty liver disease. Rom J Diabetes Nutr Metab Dis. 2019;26(4):353-60. https://doi.org/10.2478/ rjdnmd-2019-0038
10. Dhingra D, Michael M, Rajput H, Patil RT. Dietary fibre in foods: A review. J Food Sci Technol. 2012;49(3):255-66. https://doi. org/10.1007/s13197-011-0365-5

PMid:23729846

11. Wang ZQ, Yu Y, Zhang XH, Floyd EZ, Bourdreau A, Lian K, Cefalu WT. Comparing the effects of nano-sized sugarcane fiber with cellulose and psyllium on hepatic cellular signaling in mice. Int J Nanomedicine 2012;7:2999-3012. https://doi.org/10.2147/ ijn.s30887

PMid:22787396

12. Li X, Guo J, Ji K, Zhang P. Bamboo shoot fiber prevents obesity in mice by modulating the gut microbiota. Sci Rep. 2016;6:32953. https://doi.org/10.1038/srep32953

13. Rodríguez RA, Fernández-Bolaños J, Guillén R, Heredia A Dietary fiber from vegetable products as source of functional ingredients. Trends Food Sci Technol. 2006;17(1):3-15. https:// doi.org/10.1016/j.tifs.2005.10.002

14. Slavin J. Fiber and prebiotics: Mechanisms and health benefits. Nutrients. 2013;5(4):1417-35. https://doi.org/10.3390/ nu5041417

PMid:23609775

15. Yao L, Wei J, Shi S, Guo K, Wang X, Wang Q, et al. Modified lingguizhugan decoction incorporated with dietary restriction and exercise ameliorates hyperglycemia, hyperlipidemia and hypertension in a rat model of the metabolic syndrome. BMC Complement Altern Med. 2017;17(1):132. https://doi. org/10.1186/s12906-017-1557-y

PMid:28241808

16. Elkotby D, Hassam AK, Emad R, Bahgat I. Histological changes in islets of langerhans of pancreas in alloxan-induced diabetic rats following Egyptian honey bee venom treatments. Int J Pure Appl Zool. 2018;6(1):1-6.

17. Velickovic KD, Ukropina MM, Glisic RM, Cakic-Milosevic MM Effects of long-term sucrose overfeeding on rat brown adipose tissue: A structural and immunohistochemical study. J Exp Biol. 2018;221(Pt 9):jeb166538. https://doi.org/10.1242/jeb.166538 PMid:29496784

18. Marrif $\mathrm{HI}$, Al-Sunousi SI. Pancreatic $\beta$ cell mass death. Front Pharmacol. 2016;7:83. https://doi.org/10.3389/ fphar.2016.00083

PMid:27092078

19. Gasa R, Gomis R, Novials A, Marservitja M. Molecular aspects of glucose regulation of pancreatic $\beta$ cells. Mol Nutr Diabetes. 2016;11:155-68. https://doi.org/10.1016/ b978-0-12-801585-8.00013-0

20. Shanik MH, Zu Y, Skrha J, Danker R, Zick Y, Roth J. Insulin resistance and hyperinsulinemia is hyperinsulinemia the cart or the horse? Diabetes Care. 2008;31 Suppl 2:S262-8. https://doi. org/10.2337/dc08-s264

PMid: 18227495

21. Hori M, Mutoh M, Imai T, Nakagama H, Takahashi M. Possible involvement of pancreatic fatty infiltration in pancreatic carcinogenesis. JOP J Pancreas. 2016;17(2):166-75.

22. Williams JA. Regulation of acinar cell function in the pancreas. Curr Opin Gastroenterol. 2010;26(5):478-83.

PMid:20625287

23. Pierzynowski SG, Gregory PC, Filip R, Woliński J, Pierzynowska KG. Glucose homeostasis dependency on acini-islet-acinar (AIA) axis communication: A new possible pathophysiological hypothesis regarding diabetes mellitus. Nutr Diabetes. 2018;8:55. https://doi.org/10.1038/s41387-018-0062-9

24. Fischer MM, Kessler AM, de Sá LR, Vasconcellos RS, Filho FO, Nogueira SP, et al. Fiber fermentability effects on energy and macronutrient digestibility, fecal parameters, postprandial metabolite responses, and colon histology of overweight 
cats. J Anim Sci. 2012;90(7):2233-45. https://doi.org/10.2527/ jas.2011-4334

PMid:22247109

25. Sukkar AH, Lett AM, Frost G, Chambers ES. Regulation of energy expenditure and substrate oxidation by short chain fatty acids. J Endocrinol. 2019;242(2):R1-8. https://doi.org/10.1530/ joe-19-0098

PMid:31042668

26. Christiansen CB, Gabe MB, Svendsen B, Dragsted LO Rosenkilde MM, Holst JJ. The impact of short-chain fatty acids on GLP-1 and PYY secretion from the isolated perfused rat colon. Am J Physiol Gastrointest Liver Physiol. 2018;315(1):53-65. https://doi.org/10.1152/ajpgi.00346.2017

PMid:29494208

27. Huang W, Guo HL, Deng X, Zhu TT, Xiong JF, Xu YH, et al. Shortchain fatty acids inhibit oxidative stress and inflammation in mesangial cells induced by high glucose and lipopolysaccharide. Exp Clin Endocrinol Diabetes. 2017;125(2):98-105. https://doi. org/10.1055/s-0042-121493

PMid:28049222

28. Wang J, Wang $\mathrm{H}$. Oxidative stress in pancreatic beta cell regeneration. Oxid Med Cell Longev. 2017;2017:1930261. https://doi.org/10.1155/2017/1930261

PMid:28845211 